\title{
IMPACT OF TOPOGRAPHIC CORRECTION ON SOIL AND VEGETATION COVER SPECTRAL CHARACTERIZATION BY TM/LANDSAT 5 IMAGERY
}

Keywords:

Topographic correction

C-correction

Spectral characterization

Histórico:

Recebido 03/02/2016

Aceito 22/08/2016

Palavras chave: Correção topográfica Correção-C Espectral caracterização

Correspondência: flavio@dsr.inpe.br

DOI:
ABSTRACT: Several topographic correction methods have been developed to be applied to orbital imagery. The main objective of these initiatives has been focused on improving land cover mapping. Despite of some discussions that include spectral approaches, no attention has been given to the impact of such correction on the spectral characterization of different targets. That impact can influence relationships commonly explored between radiometric data from orbital imagery and biophysical and/or geophysical parameters. TM/Landsat 5 images (orbit 218, row 76) from a mountainous region located between São Paulo, Minas Gerais and Rio de Janeiro states (Brazil) were converted to surface reflectance values. Two topographic correction methods considering different sampling strategies were applied. The local illumination was taking into account during the result analysis in order to evaluate the selective effect of the topographic correction on the spectral characterization of bare soils and vegetated surfaces. The results indicated that the sampling strategy influences both the visual aspect of the topographic corrected images and the spectral characterization of targets. Spectral distortions caused by the topographic correction procedures were higher at darker illumination conditions. The topographic correction is a procedure that deserves attention when exploring spectral characterization of different targets. Sometimes it contributes positively in qualitative approaches such as mapping or digital classification, but it can imply in severe influence on quantitative approaches that are dependent on the targets spectral characterization.

\section{IMPACTO DA CORREÇÃO TOPOGRÁFICA NA CARACTERIZAÇÃO ESPECTRAL DE SOLO E COBERTURA VEGETAL POR MEIO DE IMAGENS TM/LANDSAT 5}

RESUMO: Vários métodos de correção topográfica têm sido desenvolvidos para serem aplicados a imagens orbitais. O principal objetivo dessas iniciativas tem incluído principalmente o aprimoramento de trabalhos de mapeamento. Apesar de algumas discussões a respeito das implicações dessas correções incluírem abordagens espectrais, pouca atenção tem sido dada aos seus impactos sobre a caracterização espectral de diferentes alvos. Tais impactos podem influenciar relações comumente exploradas entre dados radiométricos presentes em imagens orbitais e parâmetros biofísicos e/ ou biofísicos. Imagens do sensor TM/Landsat 5 (órbita 218 , ponto 76) de uma região montanhosa localizada entre os estados de São Paulo, Rio de Janeiro e Minas Gerais (Brasil) foram convertidas em valores de reflectância de superfície. Dois métodos de correção topográfica considerando diferentes estratégias amostrais foram aplicados. A iluminação local foi levada em consideração durante a análise dos resultados para avaliar o efeito seletivo da correção topográfica sobre a caracterização de superfícies ocupadas por solo exposto e por vegetação. Os resultados indicaram que a estratégia amostral influencia tanto o aspecto visual das imagens quanto a caracterização espectral dos alvos. Distorções espectrais ocasionadas pelos procedimentos de correção topográfica foram maiores em regiões pouco iluminadas do terreno. A correção topográfica é um procedimento que merece atenção quando se deseja explorar as propriedades espectrais dos alvos. As vezes ela contribui positivamente em abordagens qualitativas como na elaboração de mapas ou na classificação digital, mas ela pode implicar em severas alterações em abordagens quantitativas que dependem da caracterização espectral dos alvos de interesse.

Instituto Nacional de Pesquisas Espaciais - São José dos Campos, São Paulo, Brasil 


\section{INTRODUCTION}

The recent free distribution of high-resolution digital elevation models (DEM) has motivated several researchers and remote sensing data users to apply different topographic correction models to also different orbital imagery sources such as TM/Landsat 5, ETM+/Landsat 7 and HRV/SPOT. The majority of such applications are based on the potential improvement in land cover mapping using different classification strategies.

Moreira and Valeriano (2014) have evaluated the impact of some topographic correction methods to improve land cover mapping using an object-based classification procedure. They concluded that the topographic correction increased the classification performance for specific land cover classes. Similar results have been achieved by Colby (199I), Cuo et al. (2010) and Hantson and Chuvieco (20II). Vanonckelen et al (2013) presented a good and complete review about the impact of the topographic correction on land cover classification results from many authors, but despite the high quality of everything that has been done, no attention has been dedicated to the impact of such correction on the targets spectral characterization.

Several authors have dedicated attention to the topographic effects on vegetation remote sensing such as Meyer et al (1993) that applied radiometric corrections of topographically induced effects on TM/Landsat 5 data, Huang et al (2010) that evaluated these effects on estimating net primary productivity of green coniferous forest in complex terrain using also TM/Landsat 5 data and Riaño et al (2003) that explored different topographic corrections in TM/Landsat 5 data for mapping vegetation types. Interesting results have been achieved by Fan et al (20I4) proposing a sun-crown-sensor model and adapting the C-correction topographic correction logic for topographic correction of high resolution forest imagery.

Of course several result discussions have (at least superficially) included some spectral approach, but taking into account the actual importance of the spectral characterization on remote sensing quantitative applications, the impact of the topographic correction has to be evaluated under a different point of view.

In spite of having enough knowledge about the topography influence on remote sensing data, several researches have neglected it relating radiometric data with biophysical and/or geophysical parameters. Huete et al (2002), for instance, presented an overview of the radiometric and biophysical performance of MODIS vegetation indices. Their work was based on test sites located in semi-arid, savanna and tropical forest biomes where the topography did not influence significantly. Muukkonen and Heiskanen (2007) carried out biomass estimation based on standwise forest inventory data and ASTER and MODIS data also neglecting the possible topographic effects on the radiometric data extracted from the orbital imageries.

The increasing necessity to quantify biophysical and geophysical parameters from natural resources has enforced remote sensing users to be familiar with some typical orbital imagery data conversions such as Digital Numbers (DN) to TOAI reflectance or DN to surface reflectance. Such conversions have been applied in order to allow correlation analysis between spectral data and biophysical and/or geophysical parameters. Frequently researchers have faced strong constrains working under different local illumination conditions caused by both Sun positioning and topographic localization of a pixel or several pixels under study (Ponzoni et al., 20I4). When exploring quantitative remote sensing the topographic correction seems to be a potential alternative to solve many of these constrains.

As pointed out by Hantson and Chuvieco (20I I) some topographic correction methods do not include only the geometry defined by the Sun positioning and the topography. The C-correction method proposed by Teillet et al (1982) includes also the relationship between the local illumination and the resulting reflectance (ND, TOA reflectance or surface reflectance) from different land use classes. The Modified-Minnaert method proposed by Richter et al (2009) considers the surface reflectance from vegetated and non-vegetated surfaces.

Choosing a topographic correction method is also an important decision since the results can change from one method to another. Besides that, the sampling procedure adopted, even on a same method, can provide different results. Thus it is expected that any topographic correction procedure shall influence the fidelity of objects spectral characterization and such influence must be taken into account when the objective is beyond digital classifications. Therefore we analyzed and evaluated the impact of two topographic correction methods (C-correction and Modified-Minnaert algoritm) adopting two sampling strategies (spectral characterization of vegetated and non-vegetated surfaces) in a mountain region of southeastern Brazil using TM/Landsat data. Such evaluation consisted on analyzing distortion on spectral reflectance of targets caused by the topographic correction procedure considering different local illumination conditions. 


\section{MATERIAL AND METHODS}

\section{Study area}

The study area is covered by and entire TM/ Landsat 5 scene (orbit 218 row 76) from September $5^{\text {th }}$, 2011 . The central coordinates are $23^{\circ} 06^{\prime} 59^{\prime \prime}$ ' $\mathrm{S}$ and $44^{\circ}$ $58^{\prime} 49^{\prime \prime}$ ' partially including the territories of São Paulo, Minas Gerais and Rio de Janeiro states, Brazil. Figure I shows the regional localization of the study area.

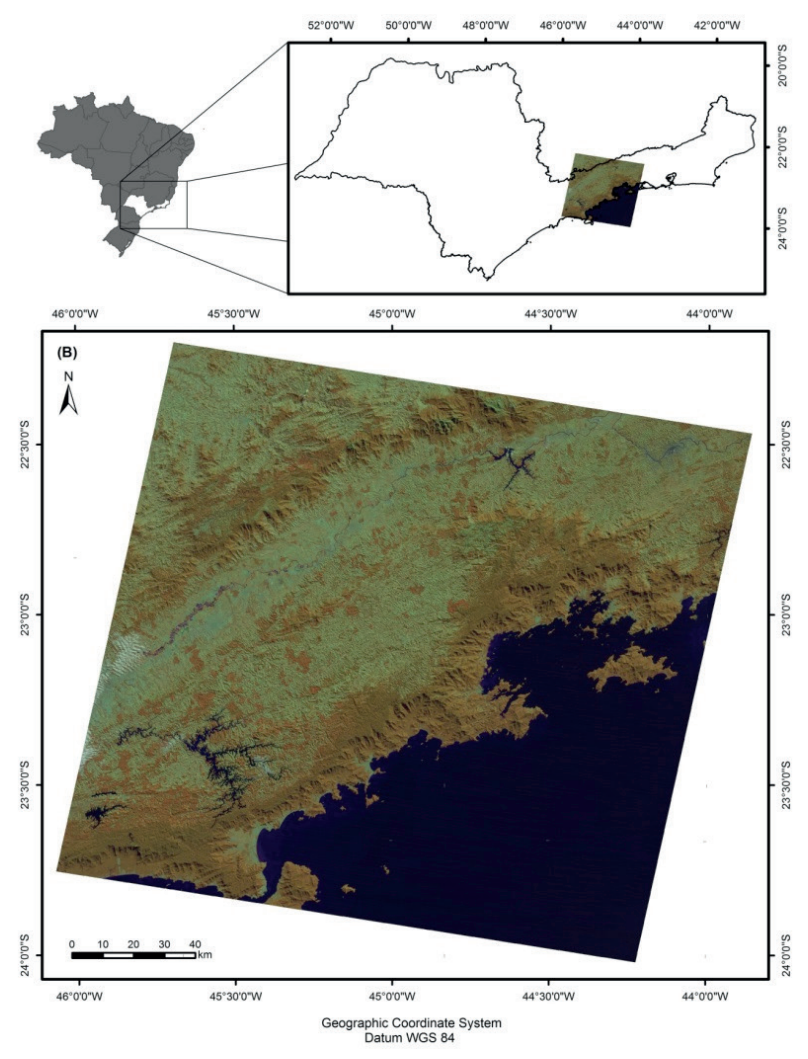

FIGURE I Study area localization in the regional context.

This entire scene includes different environments and topographic conditions. Near the ocean, in the southeastern portion of the scene, there is a relatively large altitudinal change from the ocean level toward the continent (around $800 \mathrm{~m}$ in the northwest direction). That mountainous regions is known as "Serra do Mar" and is composed by peaks and valleys covered by a very dense tropical forest. The relief is characterized by great variation in slopes and aspects. Still toward the northwest direction the terrain becomes rough with small hills. The terrain cover is dominated by different land use categories, including pasture, urban areas and commercial Eucalyptus plantations. Almost in the middle of the scene there is a valley ("Vale do Rio Paraiba") presenting a relatively flat topography (southwest to northeast direction) whose northern border is composed by another mountainous region, also covered by a very dense tropical forest called "Serra da Mantiqueira".

The idea was choosing a study area in which it would be possible to find large enough surfaces covered by homogenous portions of dense forest and bare soil, considered here as spectrally different land cover categories.

\section{Digital Number conversion}

The Digital Numbers (DN) of the TM/Landsat 5 optical images (TM spectral bands I-5 and 7) from September $5^{\text {th }}$, $201 \mathrm{I}$ were converted to Top of Atmosphere (TOA) radiance as described by Chander et al (2009). The TOA reflectance images were converted to surface reflectance through the application of the $6 \mathrm{~S}$ (Second Simulation of the Satellite Signal in the Solar Spectrum) atmospheric correction code. The evaluation of that conversion consistency was conducted analyzing the spectral characterization of well-known targets such as water bodies, bare soils and different kinds of vegetation cover.

\section{Topographic corrections}

Here we opted to test two topographic correction methods being one of them strongly spectrally dependent (C-correction) and another one dependent on the land-cover, the wavelength and the solar zenith angle (Modified-Minnaert algorithm).

The C-correction was proposed by Teillet et al (1982) and described by Hantson and Chuvieco (20II) as, where is the reflectance of a pixel $i$ in horizontal terrain at spectral band $\lambda$; is the reflectance of a pixel $i$ in rugged terrain at spectral band $\lambda ; q_{s}$ is the solar zenith angle; $g_{i}$ is the incidence angle (according the solar positioning and the topographic conditions for pixel $i$ ) and $c_{\lambda}$ is a ratio of the coefficients of a linear regression between and the surface reflectance at band $\lambda$.

$\rho_{\lambda, \mathrm{h}, \mathrm{i}}=\rho_{\lambda, \mathrm{i}}\left(\frac{\cos \theta_{\mathrm{s}}+\mathrm{c} \lambda}{\cos \gamma_{\mathrm{i}}+\mathrm{c} \lambda}\right)$

Here is given by, where $g_{i} \theta_{s}$ is the incident angle, is the solar zenith angle, $\eta_{i}$ is the slope angle, $\phi_{a}$ is the solar azimuth and $\phi_{0}$ is the slope aspect.

$\cos \gamma_{i}=\cos \theta_{s} \cdot \cos \eta_{i}+\operatorname{sen} \theta_{s} \cdot \operatorname{sen} \eta_{i} \cdot \cos \left(\phi_{a}-\phi_{0}\right)$

The mentioned linear regression is given by:

$\rho_{\lambda, \mathrm{i}}=\mathrm{b}_{\lambda}+\mathrm{m}_{\lambda} \cdot \cos \gamma_{\mathrm{i}}$ 
So, $c_{\lambda}$ is given by:

$c_{\lambda}=\left(\frac{b_{\lambda}}{m_{\lambda}}\right)$

This method is dependent on the illumination/ spectral reflectance relationship and since the regression is established by a limited number of $x$ sample points and any random sampling strategy implies extracting data from different land-cover type, the resulting is strongly dependent on the sampling procedure.

The Modified-Minnaert algorithm was proposed by Richter et al (2009) and the model changes depending if the pixel is classified as vegetation or non-vegetation and on the illumination as well (Hantson and Chuvieco, $20 \mathrm{II}$ ), where the variable $I$ is defined depending on the land-cover and wavelength. It assumes a value of 0.5 for non-vegetation areas, 0.75 for vegetated areas for spectral bands with $\lambda<720 \mathrm{~nm}$ and 0.333 for $\mathrm{I} \geq 720 \mathrm{~nm}$; $b_{i}$ is dependent on the solar zenith angle; where $t$ depends on the solar zenith angle, when $q_{\mathrm{s}}<45^{\circ}, \mathrm{t}=20^{\circ} ; 45^{\circ} \leq q_{\mathrm{s}}$ $\leq 55^{\circ}, \mathrm{t}=15^{\circ}$ and $q_{\mathrm{s}}>55^{\circ}, \mathrm{t}=10^{\circ}$.

$\beta_{\mathrm{i}}=\theta_{\mathrm{s}}+\mathrm{t}$

These two topographic correction models have been implemented on an image processing and GIS software called SPRING developed by the National Institute for Space Research (INPE), Brazil.

\section{Data analysis}

Hantson and Chuvieco (20II) have evaluated several topographic correction methods for Landsat imagery. As mentioned by these authors, the most widely used method for validating the performance of the topographic correction algorithms is the decrease in the correlation coefficients between the incident angle and the surface reflectance (or similar data available in the images from different spectral bands). Similar strategy has been explored by Gao and Zhang (2009) and MacDonald et al (2000), but Hantson and Chuvieco (20II) improved that evaluation procedure taking into account that changes in shadowing of a pixel value within the same land-cover in different slopes and aspects should decrease after the topographic correction method application and they also included a temporal approach to evaluate the robustness of the tested methods using bare soil and pine forest pixels as references. Moreira and Valeriano (2014) have considered the performance of supervised classification to evaluate the effect of the topographic correction using several methods.
Despite the relevant contributions of these evaluation efforts, none have been dedicated to evaluate the impact of the topographic correction on the spectral characterization of any land-cover type, as frequently is needed. So, we opted to evaluate the impact of both topographic correction strategies on the reflectance data from bare soils and vegetated surfaces.

Taking into account the sampling dependence of the C-correction method, two sampling procedures were conducted. The first one was based on the arbitrarily selection of 1090 samples from the entire TM/Landsat 5 scene including visible bare soils and forested areas under different topographic conditions. The second sampling procedure was based on the arbitrarily selection of 4I5 samples from forested areas also under different topographic conditions. The surface reflectance and values were extracted from these samples in order to build the linear regressions that were used to estimate values (Equation 4). So, two set of corrected images were generated: one from both bare soils and forested areas and another one from the forested area, making possible two spectral characterizations of a same target.

As mentioned, this arbitrarily sampling took into account the topographic conditions that were classified according the so called "illumination classes" that were defined based on the values. Five illumination classes were defined: Dark, Low illumination, Illuminated, High illumination and Bright. The spatial distribution of these illumination classes was made dividing the values range in five equal intervals, which were used to define the illumination classes. The sampling procedure was performed visually collecting samples from the different land-cover and illumination classes.

The Modified-Minnaert algorithm was applied according to Equations 5 and 6, generating a third set of corrected images, permitting a third spectral characterization of the same target.

The comparison between these three spectral characterizations took into account the illumination classes described above. Five pixels from each illumination class covered by bare soil and five others also from each illumination class but covered by typical tropical forest were arbitrarily selected. The surface reflectance values from the non-corrected and corrected images by both topographic correction procedures were extracted from each TM/Landsat 5 spectral bands. The non-corrected images were considered as a reference on a comparison procedure. 


\section{RESULTS}

\section{C-correction method}

Table I shows the linear regressions defined by both sampling procedures (total and vegetation).

Observing the equations coefficients presented on Table $I$ it is clear that they change according the sample strategy adopted (Total or Vegetation). Moreira and Valeriano (2014) have mentioned that the linear regressions are strongly dependent on the surface cover. When the sampling procedure is performed randomly, thus extracting surface reflectance values from different surface land-cover types, $R^{2}$ values are obviously lower than those from the linear regression established from vegetated pixels. Thus, the $c_{\lambda}$ values are also strongly impacted by the sampling procedure and the resulting corrected images are impacted.

The Modified-Minnaert algorithm was applied taking into account both the land-cover and the angular criteria described by Richter et al (2009). The resulting images were added to the GIS data bank.

Figure 2 shows part of the 219/76 TM/Landsat 5 image (3B, 4R, 5G color composition) without topographic correction (original) and corrected by the three mentioned alternatives.

The contrast applied on these color compositions was the same. At least visually the effect of the topographic correction seems to be more evident when it was applied the total sampling procedure. Images corrected by the Modified-Minnaert algorithm were clearest then the other ones, but independent of that visual appearance and the possible benefits that topographic correction eventually provided to an automatic classification procedure (mapping task), a spectral analysis should be conducted before using the corrected data in quantitative approaches such as empirical relationships between the surface reflectance and biophysical parameters from vegetation, for instance.

Balthazar et al (2012) evaluated a parametrization of ATCOR3 topographic correction method for forest cover mapping in mountain areas and their results were evaluated based on the statistical similarity of forest reflectance values between sunlit and shaded

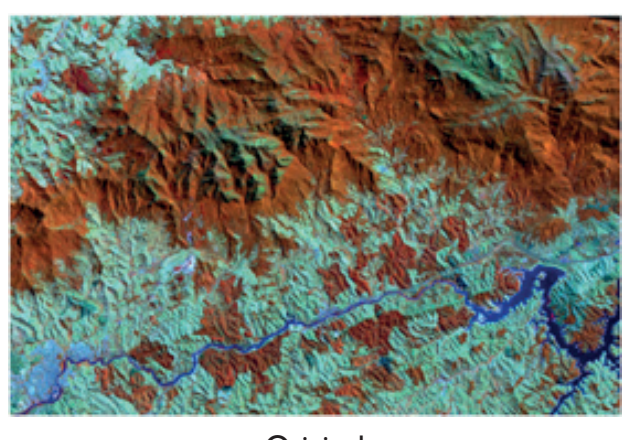

Original

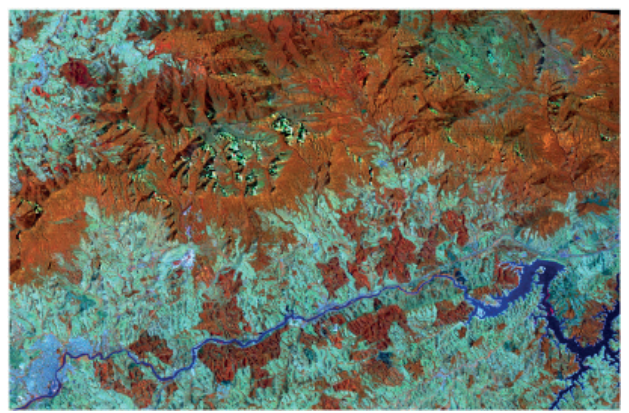

Total

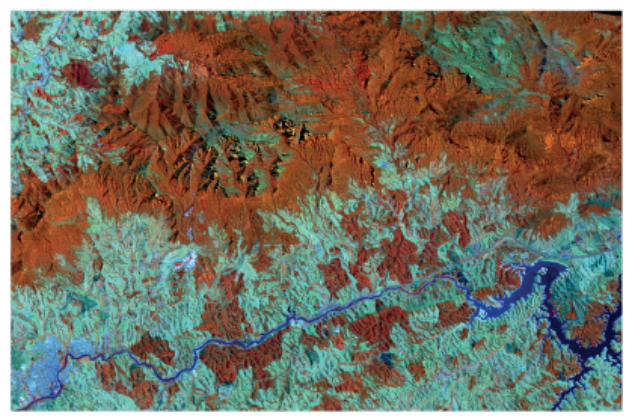

Vegetation

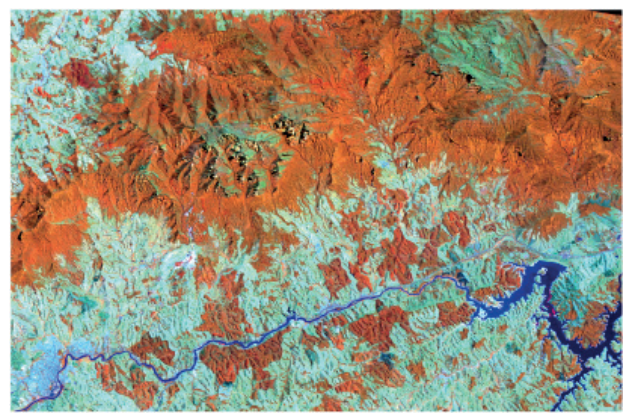

Minnaert

FIGURE 2 Part of the TM/Landsat 5 image (3B, 4R, 5G color composition) without topographic correction (Original) and corrected by three alternatives.

TABLE I Linear regressions and $c_{\lambda}$ resulting values for each TM/Landsat 5 spectral bands.

\begin{tabular}{|c|c|c|c|c|c|}
\hline Total & $\mathrm{R}^{2}$ & $\mathrm{C}_{\lambda}$ & Vegetation & $\mathrm{R}^{2}$ & $\mathrm{C}_{\lambda}$ \\
\hline$\rho_{(1, \mathrm{i})}=0.9389+8.9338 \cos \gamma \mathrm{i}$ & 0.069 & 0.105 & $\rho_{(1, i)}=0.845+I .8284 \cos \gamma \mathrm{i}$ & 0.056 & 0.462 \\
\hline$\rho_{(2, i)}^{\prime}=1.8527+17.958 \cos \gamma \mathrm{i}$ & 0.123 & 0.103 & $\rho_{(2, \mathrm{i})}^{(1, i)}=3.726+4.9904 \cos \gamma \mathrm{i}$ & 0.302 & 0.747 \\
\hline$\rho_{(3, i)}^{(2,1)}=-1.09+24.208 \cos \gamma \mathrm{i}$ & 0.109 & -0.045 & $\rho_{(3, i)}^{(2,1)}=1.8167+5.0244 \cos \gamma \mathrm{i}$ & 0.278 & 0.362 \\
\hline$\rho_{(4, i)}^{(3, i)}=21.374+60.519 \cos \gamma \mathrm{i}$ & 0.328 & 0.353 & $\rho_{(4, i)}^{(3, i)}=25.197+60.262 \cos \gamma \mathrm{i}$ & 0.445 & 0.418 \\
\hline$\rho_{(5, \mathrm{i})}^{(4, \mathrm{i})}=-3.5 \mathrm{I}+84.00 \mathrm{I} \cos \gamma \mathrm{i}$ & 0.208 & -0.0418 & $\rho_{(5, \mathrm{i})}^{(4, i)}=13.578+26.92 \cos \gamma \mathrm{i}$ & 0.401 & 0.504 \\
\hline$\rho^{(5, i)}=-5.262+59.59 \cos \gamma \mathrm{i}$ & 0.144 & -0.088 & $\rho_{(7, i)}^{(5, i)}=7.2343+11.713 \cos \gamma \mathrm{i}$ & 0.299 & 0.618 \\
\hline
\end{tabular}


slopes and on the minimization of abnormal reflectance values caused by under or overcorrection. Despite the lack of any spectral characterization, Balthazar et al (2012) results were based on the influence of different parametrization of a specific topographic correction method on reflectance values extracted from orbital data, and they concluded that such parametrization strongly influence the spectral (or radiometric) characteristics of optical images.

Spectrally speaking and taking into account the topographic positioning of bare soil and vegetation (in this case vegetation means the evergreen regional tropical forest) the spectral characterization of both cover types could be represented as shown on Figure 3.

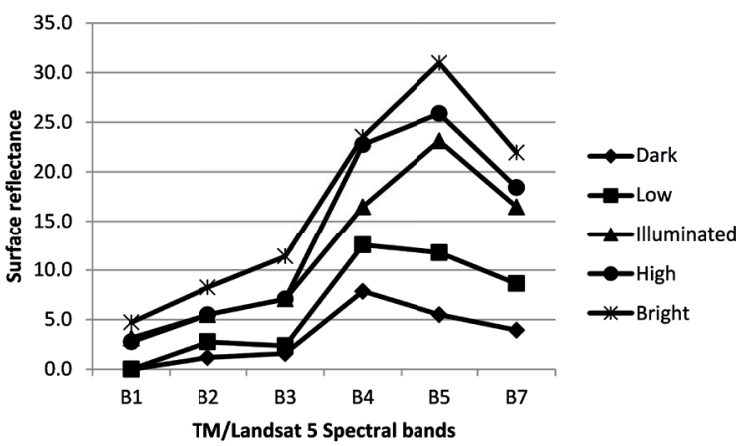

Bare soils

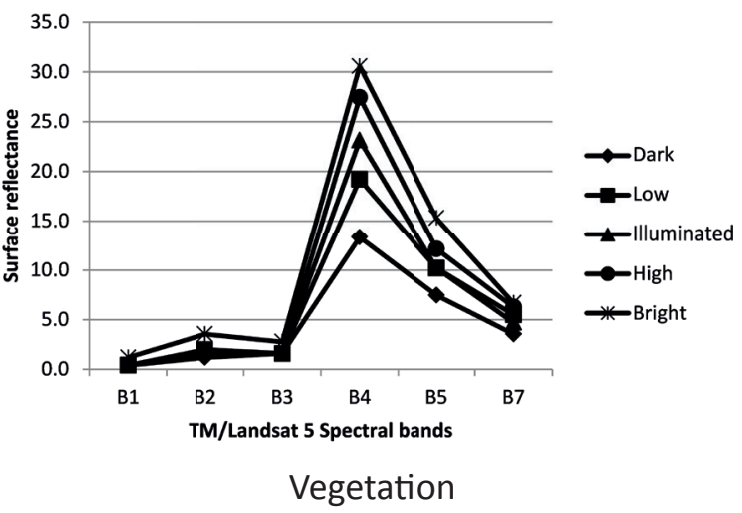

FIGURE 3 Possible spectral characterizations of bare soils and vegetation taking into account their topographic positioning.

It is clear that even considering differences in mineralogy, moisture content, structural aspects, biophysical parameters, etc, the local illumination caused by the topographic positioning strongly influences the spectral characterization of both targets.

Chen and Cao (20/2) applied a topographic correction method based on retrieval of Leaf Area Index (LAl) in mountain areas. They explored relationships between vegetation indices and $\mathrm{LAl}$ in order to evaluate the topographic method performance. The results demonstrated that these relationships were influenced by the topographic correction procedure, probably by a strong influence on the vegetation spectral characterization.

Here we assumed that the "best" spectral characterization of these targets, considering the illumination geometry specific for that TM/Landsat 5 scene, was achieved for the High illumination situation. So, it would be expected that the topographic correction should decrease the spectral distortions caused by the local illumination.

Figure 4 shows the surface reflectance curves from the one (as examples) of those five sampling pixels covered by bare soil and forest (vegetation) for each illumination class.

The Reference curves have been extracted from a specific bare soil and forest cover sample under very illuminated condition. They are the same curves shown in the graphics of Figure 4. The Original curves represent the data extracted from the non-topographically corrected images that were just converted to surface reflectance. So, the original curves are strongly influenced by the local illumination (illumination geometry plus topographic positioning) and it would be expected that the topographic correction should decrease de differences between the new surface reflectance values and the Reference ones.

As expected, the topographic corrections performed by C-correction and Modified-Minnaert algorithm increased the surface reflectance values for the darker illumination classes, maintained almost stable for the very illuminated and decreased for the clearest. Significant spectral distortions have been observed in the spectral characterization made by the C-correction model adopting the Total sampling strategy. Applying the Vegetation sampling this topographic correction procedure seemed to overestimate the surface reflectance values for both targets at darker illumination conditions. The sampling procedures (Total and Vegetation) adopted during the C-correction method application effectively influenced the spectral characterization mainly for the darker illumination conditions. The topographically corrected images generated by the Modified-Minnaert algorithm application presented higher surface reflectance values compared to those generated by the C-correction model. 

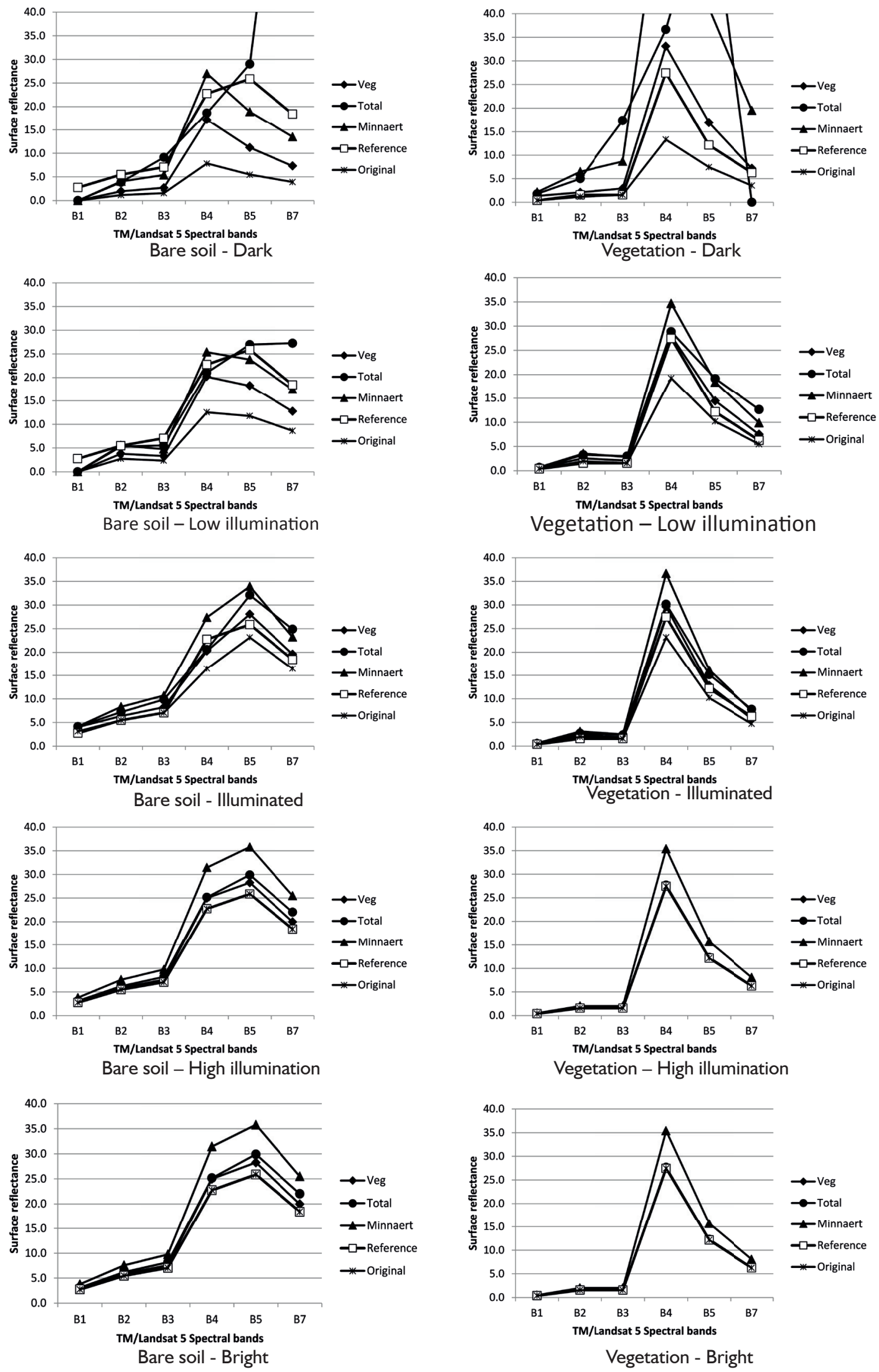

FIGURE 4 Examples of surface reflectance curves from bare soil and vegetation at each illumination classes. 


\section{CONCLUSIONS}

Choosing the topographic correction algorithm is an important aspect to be considered when exploring the spectral characterization of different targets from orbital data.

The sampling strategy inherent to the C-correction model influences both the visual aspect of the topographic corrected images and the spectral characterization of targets. The Modified-Minnaert algorithm provided higher surface reflectance values than those estimated by the C-correction model, independent on the local illumination condition.

Spectral distortions caused by the topographic correction procedures were higher at darker illumination conditions.

The topographic correction is a procedure that deserves attention when exploring spectral characterization of different targets. Sometimes it contributes positively in qualitative approaches such as mapping or digital classification, but it can imply in severe influence on quantitative approaches that are dependent on the targets spectral characterization.

\section{ACKNOWLEDGMENTS}

The authors are scholarship holders of CNPq, the Brazilian Council for Science and Technology. We also express our gratitude to Dr. Márcio de Morisson Valeriano and Mr. Eder Paulo Moreira for exchanging ideas and concepts that have been incorporate to this paper.

\section{REFERENCES}

BALTHAZAR, V.; VANACKER, V.; LAMBIN, E.F. Evaluation and parametrization of ATCOR3 topographic method for forest cover mapping in mountain areas. International Journal of Applied Earth Observation and Geoinformation. I8, 436-450, 2012.

CHANDER, G., MARKHAM, B. L., HELDER, D. L. Summary of current radiometric calibration coefficients for Landsat MSS, TM, ETM+ and EO-I ALI sensors. Remote Sensing of Environment. I 13, 893-903, 2009.

CHEN, W.; CAO, C. Topographic correction-based retrieval of leaf area index in mountain areas. Journal of Mountain Science. 9, 166-174, 2012.

COLBY, J. D. Topographic normalization in rugged terrain. Photpgrammetric Engineering and Remote Sensing. 57(5), 53I-537, I99I.

CUO, L., VOGLER, J. B., FOX, J. M. Topographic normalization for improving vegetation classification in a mountainous watershed in Northren Thailand. International Journal of Remote Sensing. 32(I I), 3037-3050, 2010
FAN, Y.; KOUKAL, T.; WEISBERG, P.J. A sun-crown-sensor model and adapted $\mathrm{C}$-correction logic for topographic correction of high resolution forest imagery. Journal of Photogrammetry and Remote Sensing. 96, 94-105, 2014.

Gao, Y., Zhang, W. A simple empirical topographic correction method for ETM+ imagery. Internation Journal of Remote Sensing. 30, 2259-2275, 2009.

Hantson, S., Chuvieco, E. Evaluation of different topographic correction methods for Landsat imagery. International Journal of Applied Earth Observation and Geoinformation. 13, 691-700, 201 I.

Huete, A.; Didan, K.; Miura, T.; Rodriguez, E.P.; Gao, X.; Ferreira, L. G. Overview of the radiometric and biophysical performance of the MODIS vegetation índices. Remote Sensing of Environment. 83, 195-213, 2002.

Huang, W.; Zhang, L.; Furumi, S.; Muramatsu, K.; Daigo, M.; li, P. Topographic effects on estimating net primary productivity of green coniferous forest in complex terrain using Landsat data: a case study of Yoshimo Mountain, Japan. International Journal of Remote Sensing. 3I(I I), 294I-2957, 20 I0.

McDonald, E. R. Wu, X., Cacceta, P. A., Campbell, N. A. Illumination correction of Landsat TM data in south east NSW. Paper Presented at: Proceedings of the Tenth Australasian Remote Sensing Conference, 20I I.

Meyer, P.; Itten, K. I.; Kellenberger, T.; Sandmeier, S.; Sandmeier, R. Radiometric corrections of topographically induced effects on Landsat TM data in an alpine environment. Journal of Photogrammetry and Remote Sensing. 48(4), 17-28, 1993.

Moreira, E. P., Valeriano, M. M. Application and evaluation of topographic correction methods to improve land cover mapping using object-based classification. International Journal of Applied Earth Observation and Geoinformation. 32, 208-217, 2014

Muukkonen, P.; Heiskanen, J. Biomass estimation over large area based on standwise forest inventory data and ASTER and MODIS satellite data: A possibility to verify canrbon inventories. Remote Sensing of Environment. 107, 617624, 2007.

Ponzoni, F., J., Silva, C. B., Santos, S. B., Montanher, O., Santos, T. B. Local illumintation influence on vegetation indices and plant Area Index (PAI) relationships. Remot Sensing. 6, 6266-6282, 2014.

Riaño, D.; Chuvieco, E.; Salas, J.; Aguado, I. Assessment of different topographic corrections in Landsat-TM data for mapping vegetation types (2003). IEEE Transactions on Geoscience and Remote Sensing. 4I(5), I056- I06I, 2003. 
Richter, R., Kellenberger, T., Kaufmann, H. Comparison of topographic correction methods. Remote Sensing. I, 184-196, 2009.

Teillet, P. M., Guindon, B., Goodenough, D. G. On the slopeaspect correction of multispectral scanner data. Canadian Journal of Remote Sensing. 8, 84-106, 1982.
Vanonckelen, S., Lhermitte, S., Rompaey, A. V. The effect of atmospheric and topographic correction methods on land cover classification accuracy. International Journal of Applied Earth Observation and Geoinformation. 24, 9-21, 2013. 
